\title{
Early childhood maltreatment experience and later sexual behavior in Brazilian adults undergoing treatment for substance dependence
}

\author{
Alessandra Diehl, ${ }^{1}$ iD Jales Clemente, ${ }^{1}$ Sandra C. Pillon, ${ }^{2}$ Paulo R.H. Santana, ${ }^{3}$ iD Claudio J. da \\ Silva, ${ }^{1}$ Jair de J. Mari ${ }^{1}$ iD \\ ${ }^{1}$ Departamento de Psiquiatria, Universidade Federal de São Paulo (UNIFESP), São Paulo, SP, Brazil. ${ }^{2}$ Departamento de Enfermagem \\ Psiquiátrica e Ciências Humanas, Escola de Enfermagem de Ribeirão Preto, Centro Colaborador da Organização Pan-Americana de Saúde \\ (OPAS)/Organização Mundial da Saúde (OMS) para o Desenvolvimento da Pesquisa em Enfermagem, Universidade de São Paulo (USP), \\ Ribeirão Preto, SP, Brazil. ${ }^{3}$ Instituto Bairral, Itapira, SP, Brazil. iD AD https://orcid.org/0000-0002-9252-3284, iD PRHS https://orcid.org/ \\ 0000-0002-2381-2429, iD JJM https://orcid.org/0000-0002-5403-0112
}

\begin{abstract}
Objective: To investigate the prevalence of early childhood maltreatment and associations with later sexual behavior among adult substance users.

Methods: A cross-sectional study enrolled 134 substance dependents who sought outpatient care in São Paulo, Brazil. Childhood trauma prevalence was assessed using the Childhood Trauma Questionnaire (CTQ). The Sexual Addiction Screening Test (SAST), drug of choice (DOC), and sexual behavior were also investigated.

Results: The sample was composed predominantly of single adult males $(76.1 \%)$, with alcohol as the DOC (73.9\%). Experiences of emotional neglect $(88.1 \%)$, emotional abuse $(80.6 \%)$, physical neglect $(78.4 \%)$, physical abuse $(64.2 \%)$, and sexual abuse (31.3\%) were prevalent. Women were more likely to have been sexually abused (OR $2.9,95 \% \mathrm{Cl} 1.15-7.61)$ and physically abused $(\mathrm{OR} 3.7,95 \% \mathrm{Cl} 1.31$ 10.6) in childhood. Those who were sexually abused in adulthood were more likely to have suffered physical abuse in childhood (OR $6.9,95 \% \mathrm{Cl} 1.45-11.8$ ). The odds of having been sexually abused in childhood were higher among subjects who reported to have exchanged sexual favors for drugs (OR 5.7, 95\% Cl 1.35-9.64) and to have been sexually abused in adulthood (OR 6.1, 95\% $5.2-12.36$ ). Conclusion: Physical and sexual abuse in childhood are highly prevalent in substance-dependent adults, and are associated with sexual revictimization and high-risk sexual behavior in adulthood.
\end{abstract}

Keywords: Adult survivors of child abuse; child maltreatment; substance-related disorders; sexual behavior

\section{Introduction}

Child maltreatment $(\mathrm{CM})$ is a complex global problem which encompasses physical and emotional mistreatment, sexual abuse, neglect, and negligent child care, as well as commercial sexual exploitation and trafficking of minors. ${ }^{1}$ It is recognized internationally as a severe public health, human rights, legal, and social issue. Violent and traumatic events in childhood have major repercussions on mental and physical health, resulting in immediate and/or long-term harm to the child's dignity and development. ${ }^{1,2}$

CM has been reported by one in every four adults, while one in five women and one in 13 men worldwide report being sexually abused in childhood. ${ }^{2}$ In Brazil, an average of three allegations of child and adolescent sexual exploitation were registered every hour in $2014 .^{3}$ Almost $21.7 \%$ of Brazilians report childhood violence at

Correspondence: Alessandra Diehl, Departamento de Psiquiatria, Universidade Federal de São Paulo, Rua Borges Lagoa, 570, Vila Clementino, CEP 04038-020, São Paulo, SP, Brazil.

E-mail: alediehl@terra.com.br

Submitted Dec 28 2017, accepted Jun 28 2018, Epub Dec 062018. least once over the course of their lives, according to data from the II National Alcohol and Drugs Survey. ${ }^{4}$

Another survey conducted by Zanoti-Jeronymo et al. in a multistage sample of 3,007 individuals from all Brazilian regions, aged 14 or older, from 2005-2006 found a prevalence of physical abuse in childhood of $44.1 \%$ (33.8\% moderate, $10.3 \%$ severe). ${ }^{5}$ In the same sample, the prevalence of exposure to parental violence was $26.1 \%(7.5 \%$ moderate and $18.6 \%$ severe).

Adults with substance use disorders have reported higher rates of child sexual abuse and neglect than their counterparts without such disorders. ${ }^{6-8}$ About $40-90 \%$ of substance users report a history of childhood abuse; individuals who experience abuse in childhood are twice as likely to have substance use disorders in adulthood when compared to the general population. ${ }^{6}$ Physical, sexual, and emotional abuse or neglect have been identified as

How to cite this article: Diehl A, Clemente J, Pillon SC, Santana $\mathrm{PRH}$, da Silva CJ, Mari JJ. Early childhood maltreatment experience and later sexual behavior in Brazilian adults undergoing treatment for substance dependence. Braz J Psychiatry. 2019;41:199-207. http:// dx.doi.org/10.1590/1516-4446-2017-0020 
predictors of persistent dependence on alcohol (odds ratio [OR] 1.50-2.99, 95\% confidence interval [95\% Cl] 1.04-4.68) and nicotine (OR 1.37-1.74, 95\% Cl 1.13-2.11). ${ }^{9}$ It has been estimated that $30 \%$ of psychiatric disorders diagnosed in adults might be directly linked to childhood experiences.

These findings suggest that child abuse increases the likelihood of substance use and doubles the incidence of psychopathological comorbidity. ${ }^{10}$ It also seems to be associated with earlier drug use initiation ${ }^{11-13}$ and may play a significant role in the development and severity of dependence on alcohol, nicotine, and other drugs, through an internalizing pathway involving negative effects. ${ }^{14-16}$

The international literature suggests that $\mathrm{CM}$ is associated with a number of mental, social, and physical health problems in adulthood. Psychosis, depression, anxiety, suicidality, posttraumatic stress disorder, and early polydrug abuse are among the psychiatric conditions mentioned, ${ }^{6}$ while antisocial behavior, interpersonal and academic difficulties, aggression, poor coping skills, low self-esteem, emotional instability, criminal behavior, hopelessness, revictimization, high-risk sexual behavior in adulthood, ${ }^{17}$ and physical health problems ${ }^{18,19}$ stand out among the problems reported. Individuals who have been sexually abused may exhibit elevated rates of psychiatric and substance use disorders as a consequence of their traumatic experience. Any level of sexual abuse may be associated with polydrug use in later life ${ }^{10}$ and high-risk sexual behavior in adulthood. ${ }^{17,20}$

These conditions seem to have gender-related variances in diverse dependence development outcomes. ${ }^{21-23}$ Women are more likely to report sexual, physical, and emotional abuse, at rates varying from 77 to $90 \%$. A study conducted in Mexico with 112 female inmates found that revictimization abuse occurred at a rate of $78.1 \% .^{19}$

The relationship between $\mathrm{CM}$, high-risk sexual behavior in adulthood, and drug use has not been extensively investigated. ${ }^{11,19,24} \mathrm{~A}$ conceptual model that tries to explain the connection between $\mathrm{CM}$, later risky sexual behavior, and alcohol consumption concurs with Miller, who hypothesized the following mechanisms: a) substance use to cope with early CM trauma (more studies with alcohol than any other drug); b) poor sexual adjustment (unprotected sex, multiple partners, sex trading, and adult sexual revictimization; c) abuse-related mental illness (paraphilic disorders); and d) riskier social networks (increased odds of substance use). ${ }^{25}$

In this study, we hypothesized that adults who seek treatment for substance abuse would present with high rates of $\mathrm{CM}$ prevalence, and that these rates would be significantly higher in women. Furthermore, we hypothesized that substance-dependent patients who seek treatment with a history of $\mathrm{CM}$ might report alcohol and cocaine as their drugs of choice (DOC) and adoption of high-risk sexual behaviors in adulthood.

Little is known about the prevalence of CM experienced by adult substance users in low- and middle-income countries (LMIC), especially in Latin American countries, which present the highest estimates of childhood trauma in the world. ${ }^{26,27}$ Although $\mathrm{CM}$ has a high worldwide economic cost and serious lifelong consequences, studies are still scarce. ${ }^{2}$ The present study advances in relation to prior research by examining and discussing a combination of clinical aspects related to early child sexual abuse, maltreatment experiences, and later sexual behavior in adulthood (mainly sexual addiction and paraphilic symptoms) in a clinical sample of Brazilian drug users. To the best of our knowledge, there is no other study on this topic. Our aim was to investigate the prevalence of early CM experiences and its association with later sexual behavior among adult substance-dependent patients undergoing treatment.

\section{Methods}

This cross-sectional study was conducted at a public specialized outpatient unit for addiction treatment (Ambulatório Médico de Especialidades de Psiquiatria Dra. Jandira Masur), in São Paulo, Brazil. The sample comprised consecutive admissions of 134 drug users, male and female, aged 18 to 60 years. Data collection was conducted from February 2013 to January 2014. This study was approved by the ethics committee of Universidade Federal de São Paulo (UNIFESP; protocol 56520), and all subjects provided written informed consent. The research protocol was self-administered. No refusals were recorded.

\section{Measures}

A semi-structured questionnaire containing the following items was administered:

1. Sociodemographic data: age, educational level, ethnicity, marital status, monthly income, employment status, and religious affiliation.

2. Sexual behavior questions: sexual activity in the preceding 12 months, history of human immunodeficiency virus (HIV) infection, frequency of condom use with casual and regular sexual partners, current masturbation, sexual orientation, sex with sex workers in the preceding 12 months, and paraphilic thoughts in the preceding 12 months, detected by the items "Have you had atypical sexual desires in the last 12 months?" or "Do you have intense sexually arousing fantasies, sexual urges, sexual behaviors generally involving children, animals, cadavers, or any other, such as pleasure in observing people having sex or naked?" This item was considered the dependent variable and elicited dichotomously (yes or no answer).

3. Drug of choice (DOC): this information was elicited directly via the question "What is your drug of choice?" Although substance users often meet diagnostic criteria for multiple drug dependence, the patient's DOC is usually included in clinical records to assist in user profile identification for appropriate case management. ${ }^{28}$

4. Childhood Trauma Questionnaire (CTQ): this retrospective, self-report instrument developed by Bernstein \& Fink ${ }^{29}$ evaluates the history of physical and emotional neglect, physical abuse, and emotional abuse in adolescents and adults (age 12 years or older). It consists of 28 affirmative statements related to situations which may have taken place in childhood, plus their frequency, scored on 
a five-point Likert scale. Scores range from 28 to 140 . The CTQ has excellent internal consistency in all subscales; for example, the Cronbach's alpha for the physical neglect subscale was 0.66 , and that for sexual abuse, 0.92. Furthermore, CTQ scores have been found to be stable on analysis of test-retest reliability. This instrument is widely used in research, forensics, and clinical practice. In Brazil, a Portuguese-language version was validated by Grassi-Oliveira et al., ${ }^{30}$ who confirmed ease of understanding and semantic validity.

5. Sexual Addiction Screening Test (SAST): this 25-item self-report instrument was developed by Carnes $^{31}$ to identify potential cases of sex addiction. Silveira et al. ${ }^{32}$ validated the Brazilian version of SAST with a sensitivity of 0.83 , specificity of 0.75 , and excellent internal consistency (Cronbach's alpha $=0.89$ ). Each affirmative answer is assigned one point, while negative answers receive no points. The cutoff score in the Brazilian version was 6 .

\section{Statistical analyses}

Categorical variables are described as absolute and relative frequencies, and continuous variables, as mean and standard deviation (SD). Bivariate statistical analyses included the chi-square test $\left(\chi^{2}\right)$ to evaluate association among CTQ domains (dichotomous variables) and sociodemographic characteristics and DOC and adult sexual behaviors, considering significance at $p<0.05$. The KolmogorovSmirnov test of normality was applied to the numerical variables (CTQ total score) and confirmed asymmetric distribution. Hence, the Mann-Whitney $U$ and Kruskal-Wallis tests were used to evaluate differences between the groups of variables among the dependent variable categories (CTQ total score) and sociodemographic variables, DOC, and sexual behavior in adulthood.

Adjusted ORs and $95 \%$ Cls were calculated for multivariate analyses. Dependent variables (physical and emotional neglect; physical, sexual, and emotional abuse) were categorized dichotomously as present or absent in childhood, and estimated individually with the independent variables (demographic: age, gender, marital status, race, religion, educational level, employment; DOC: alcohol, tobacco, cannabis, cocaine, crack cocaine; sexual behavior in adulthood: sexual orientation, sex addiction, paraphilia, condom use with regular partner, condom use with casual partner, exchanging sexual favors for drugs, masturbation, homosexual intercourse, HIV, and sexual abuse) with binary logistic regression. The exit criterion for all variables introduced in each model was $p<0.10$. Nonsignificant variables were removed one by one by backward stepwise selection, yielding a final regression model containing only those variables with the highest statistical significance. ${ }^{33}$ Again, significance was accepted at $p<0.05$ for all statistical tests. Data were analyzed in SPSS version 17 and Stata version 8.0.

\section{Results}

Sociodemographic data are displayed in Table 1. Patients were predominantly male $(76.1 \%)$ and single $(76.1 \%)$, with a mean age of 34 years (SD 10.6 years, range 18 to 66 years). The typical subject profile was Caucasian $(68.8 \%)$, non-Catholic $(70.1 \%)$, employed $(60.6 \%)$, and with fewer than 8 years of formal education $(79.1 \%)$. Most of the sample had experienced situations of physical neglect $(n=105 ; 78.4 \%)$, emotional neglect $(n=118 ; 88.1 \%)$, emotional abuse $(n=108 ; 80.6 \%)$, physical abuse $(n=86$; $64.2 \%)$, and sexual abuse ( $n=42 ; 31.3 \%)$.

\section{Sociodemographic data and child maltreatment (CM)}

On bivariate analysis, the variables gender, race, and religion were associated with $\mathrm{CM}$ (emotional neglect, physical, and sexual abuse). There was a predominance of women who reported physical abuse (86.7 vs. $65.2 \%$, $\left.\chi_{(1)}^{2}=5.004 p=0.025\right)$ and sexual abuse (53.3 vs. $28.3 \%$, $\left.\chi_{(1)}^{2}=6.300 \mathrm{p}=0.012\right)$ in childhood when compared to men. Women had a significantly higher mean rate of $\mathrm{CM}$ in childhood than men ( $73.1 \%$ vs. $57.7 \%, p=0.038)$. Caucasian subjects also reported a higher prevalence of CTQ emotional neglect than non-Caucasian ones (100 vs. $88.6 \%, \chi_{(1)}^{2}=9.934 p=0.002$ ). As for religion, the non-Catholic subjects reported higher rates of emotional abuse when compared to Catholics (86.2 vs. $67.5 \%$, $\left.\chi_{(1)}^{2}=6.255 p=0.012\right)$. Non-Catholic participants had higher average CTQ rates when compared to Catholics (66.8 vs. $47 \%, p=0.006)$. The physical neglect and emotional abuse domains were not significantly associated with any particular sociodemographic characteristics in the sample.

\section{Drug of choice and child maltreatment (CM)}

Regarding DOC, the majority of childhood maltreatment patients reported tobacco use $(81.1 \%)$, and $83 \%\left(\chi_{(1)}^{2}=\right.$ $5.175 p=0.023$ ) of this sample reported emotional abuse in childhood. In addition, there was a predominance of cocaine (73.9\%) and alcohol (73.9\%) users in the sample, but without statistical significance (Table 2). Subjects who reported emotional neglect had higher rates of smoking (91.7\%) when compared to non-smokers (75\%); alcohol users presented higher CTQ scores (mean 65.8, $\mathrm{p}=$ $0.026)$. Other CTQ domains did not differ in the sample in terms of DOC (Table 2).

\section{Sexual behavior and child maltreatment (CM)}

Sex-related conditions and the main CTQ domain in this sample are presented in Table 3 . Subjects with paraphilic thoughts (97.9 vs. $\left.81.2 \%, \chi_{(1)}^{2}=5.586 p=0.018\right)$ and condom use with stable partner (97.7 vs. $80.6 \%, \chi_{(1)}^{2}=$ $7.153 p=0.007)$ reported more physical negligence. Sex addiction (89.5 vs. 61.9\%, $\left.\chi_{(1)}^{2}=9.560 \mathrm{p}=0.002\right)$, exchanging sexual favors for drugs (92.9 vs. $66 \%, \chi_{(1)}^{2}=$ $4.167 \mathrm{p}=0.041)$, and having suffered abuse in adulthood $\left(90.5\right.$ vs. $\left.66 \%, \chi_{(1)}^{2}=4.975 p=0.026\right)$ were predominant in subjects with a history of physical abuse in childhood. Furthermore, homosexual intercourse (54.8 vs. $27.8 \%$, $\left.\chi_{(1)}^{2}=7.451 \mathrm{p}=0.006\right)$, exchanging sexual favors for drugs (78.6 vs. $\left.30.1 \%, \chi_{(1)}^{2}=12.585 \mathrm{p}<0.001\right)$, and sexual abuse in adulthood (85.7 vs. $24.0 \%, \chi_{(1)}^{2}=29.168$ $\mathrm{p}<0.001)$ were prevalent among those who reported 
Table 1 Sociodemographic characteristics, child abuse and neglect (physical, emotional, sexual), and CTQ domains ( $\mathrm{n}=134$ )

\begin{tabular}{|c|c|c|c|c|c|c|c|}
\hline & \multirow[b]{2}{*}{ Total } & \multicolumn{2}{|c|}{ Neglect } & \multicolumn{3}{|c|}{ Abuse } & \multirow[b]{2}{*}{ CTQ (mean rank)* ${ }^{* \dagger}$} \\
\hline & & Physical & Emotional & Physical & Sexual & Emotional & \\
\hline \multicolumn{8}{|l|}{ Age (years)* } \\
\hline $15-29$ & 39.6 & 87.5 & 95.8 & 72.9 & 43.8 & 91.7 & 68.6 \\
\hline $30-49$ & 79.1 & 86.0 & 100 & 66.0 & 30.0 & 88.0 & 58.2 \\
\hline$>50$ & & 83.3 & 91.7 & 75.0 & 25.0 & 83.3 & 54.2 \\
\hline \multicolumn{8}{|l|}{ Gender $r^{\ddagger}$} \\
\hline Male & 76.1 & 88.0 & 97.8 & 65.2 & 28.3 & 87.0 & 57.7 \\
\hline Female & 23.9 & 80.0 & 93.3 & 86.7 & 53.3 & 93.3 & 73.1 \\
\hline \multicolumn{8}{|l|}{ Marital status } \\
\hline Single & 76.1 & 89.9 & 97.1 & 66.7 & 29.0 & 87.0 & 61.1 \\
\hline Married & 23.9 & 80.8 & 96.2 & 75.0 & 40.4 & 90.4 & 60.7 \\
\hline \multicolumn{8}{|l|}{ Race $^{\ddagger}$} \\
\hline Caucasian & 68.8 & 89.3 & 100.0 & 70.2 & 34.5 & 90.5 & 62.5 \\
\hline Non-Caucasian & 31.3 & 77.1 & 88.6 & 71.4 & 34.3 & 82.9 & 54.0 \\
\hline \multicolumn{8}{|l|}{ Religion } \\
\hline Non-Catholic & 70.1 & 80.9 & 98.9 & 74.2 & 36.0 & 91.0 & 66.8 \\
\hline Catholic & 29.9 & 72.5 & 90.9 & 70.5 & 30.3 & 81.8 & 47.0 \\
\hline \multicolumn{8}{|l|}{ Schooling (years) } \\
\hline$>8$ & 79.1 & 78.9 & 87.2 & 74.0 & 35.4 & 87.5 & 57.1 \\
\hline$<8$ & 15.7 & 76.0 & 92.0 & 65.0 & 35.0 & 95.0 & 65.0 \\
\hline \multicolumn{8}{|l|}{ Employed } \\
\hline No & 39.4 & 82.1 & 97.4 & 70.5 & 29.5 & 87.2 & 53.0 \\
\hline Yes & 60.6 & 90.0 & 93.3 & 76.7 & 36.7 & 96.7 & 58.3 \\
\hline
\end{tabular}

Data presented as \%, unless otherwise specified.

Values in bold are statistically significant.

$\mathrm{CTQ}=$ Childhood Trauma Questionnaire; $\mathrm{df}=$ degrees of freedom .

* Kruskal-Wallis, ${ }^{\dagger}$ Mann-Whitney, ${ }^{\ddagger}$ chi-square $\left(\chi^{2}[\mathrm{df}]\right) U$.

sexual abuse. Higher mean CM rates were found among subjects with sex addiction (71.4\%), those who used a condom with casual partners $(56.1 \%)$, those who had homosexual intercourse $(75.6 \%)$, those who exchanged sexual favors for drugs, and those who had suffered sexual abuse in adulthood (84.7\%).

\section{Logistic regression model}

Physical neglect

Increased ORs of physical neglect in childhood were found among single subjects (OR $4.1,95 \% \mathrm{Cl}$ 1.5310.98), Caucasians (OR 4.0, 95\% Cl 1.49-10.20), cocaine users (OR 5.4, 95\% Cl 1.53-12.07), whose who used condoms with a stable partner (OR $4.9,95 \% \mathrm{Cl} 1: 20-$ 10.49 ), those with paraphilic thoughts (OR $7.0,95 \% \mathrm{Cl}$ $1.55-16.8$ ), and those with sex addiction (OR $6.5,95 \% \mathrm{Cl}$ 2.22-9.02) (Table 4).

Emotional neglect

Increased ORs of emotional neglect in childhood were observed among single subjects (OR $4.0,95 \% \mathrm{Cl} 1.96-9.71$ ), Caucasians (OR 4.8, 95\% $\mathrm{Cl}$ 2.14-7.38), non-Catholics (OR 5.4, 95\% Cl 1.48-8.04), cannabis users (OR 3.3, 95\% Cl 1.14-9.96), those with paraphilic thoughts (OR 7.2, 95\% $\mathrm{Cl} 2.28-17.15)$, and those with sex addiction (OR 7.5, $95 \% \mathrm{Cl}$ 2.32-9.20).
Physical abuse

Increased ORs of physical abuse in childhood were found in women (OR 3.7, 95\% Cl 1.31-10.6), non-Catholics (OR $2.6,95 \% \mathrm{Cl} 1.07-8.65)$, victims of sexual abuse in adulthood (OR 6.9, 95\% Cl 1.45-11.8), and sex addicts (OR $5.9,95 \% \mathrm{Cl} 2.38-9.04)$.

\section{Sexual abuse}

Increased ORs of sexual abuse in childhood were found in women (OR $2.9,95 \% \mathrm{Cl} 1.15-7.61)$, heterosexuals (OR $3.9,95 \% \mathrm{Cl} 1.45-11.8$ ), those who reported having suffered sexual abuse in adulthood (OR 6.1, 95\% Cl 5.2-12.36), and those who exchanged sexual favors for drugs (OR 5.7, 95\% $\mathrm{Cl}, 1.35-9.64)$.

\section{Emotional abuse}

ORs of emotional abuse in childhood were higher among Caucasians (OR 2.7, 95\% Cl 1.10-5.05), non-Catholics (OR 3.0, 95\% Cl 1.19-7.68), cannabis users (OR 2.9, 95\% $\mathrm{Cl} 1.01-6.80)$, and heterosexuals (OR 2.5, 95\% Cl 1.14-6.44).

\section{Discussion}

The main findings of the present study indicate high rates of physical neglect $(78.4 \%)$, emotional neglect $(88.1 \%)$, emotional abuse $(80.6 \%)$, and sexual abuse $(31.3 \%)$ among care-seeking substance-dependent adults. CM 
Table 2 Drug of choice, child abuse and neglect (physical, emotional, sexual), and CTQ domains ( $n=134$ )

\begin{tabular}{|c|c|c|c|c|c|c|c|}
\hline & \multirow[b]{2}{*}{ Total } & \multicolumn{2}{|c|}{ Neglect } & \multicolumn{3}{|c|}{ Abuse } & \multirow[b]{2}{*}{ CTQ* (mean rank) } \\
\hline & & Physical & Emotional & Physical & Sexual & Emotional & \\
\hline \multicolumn{8}{|c|}{ Alcohol $^{\dagger}$} \\
\hline Yes & 73.9 & 85.4 & 98.9 & 74.2 & 30.3 & 86.5 & 65.8 \\
\hline No & 26.1 & 87.9 & 90.9 & 60.6 & 45.5 & 93.9 & 49.7 \\
\hline \multicolumn{8}{|c|}{ Tobacco $^{\dagger}$} \\
\hline Yes & 81.1 & 84.4 & 96.9 & 72.9 & 36.5 & 91.7 & 62.3 \\
\hline No & 18.9 & 91.7 & 95.8 & 58.3 & 25.0 & 75.0 & 53.4 \\
\hline \multicolumn{8}{|c|}{ Cannabis $^{\dagger}$} \\
\hline Yes & 63.4 & 85.0 & 98.8 & 70.0 & 33.8 & 91.2 & 62.7 \\
\hline No & 36.6 & 88.1 & 92.9 & 71.4 & 35.7 & 83.3 & 59.2 \\
\hline \multicolumn{8}{|c|}{ Cocaine $^{\dagger}$} \\
\hline Yes & 73.9 & 89.0 & 96.7 & 69.2 & 36.3 & 89.0 & 64.6 \\
\hline No & 26.1 & 77.4 & 96.9 & 74.2 & 29.0 & 87.1 & 52.2 \\
\hline \multicolumn{8}{|c|}{ Crack-cocaine $^{\dagger}$} \\
\hline Yes & 38.8 & 84.8 & 95.7 & 69.6 & 32.6 & 91.3 & 58.7 \\
\hline No & 61.2 & 86.8 & 97.4 & 71.1 & 35.5 & 86.8 & 63.2 \\
\hline
\end{tabular}

Data presented as \%, unless otherwise specified.

Values in bold are statistically significant.

$\mathrm{CTQ}=$ Childhood Trauma Questionnaire; $\mathrm{df}=$ degrees of freedom

* Mann-Whitney $U,{ }^{\dagger}$ Chi-square $\left(\chi_{[\text {dff] }}^{2}\right)$.

rates were higher for women than for men. Estimates of $\mathrm{CM}$ in the general population indicate that nearly one-quarter of adults (22.6\%) worldwide have suffered physical abuse during childhood, $36.3 \%$ experienced emotional abuse, and $16.3 \%$ experienced physical neglect, with no significant differences between boys and girls. ${ }^{2}$ We also observed an association between CM and likelihood of sex addiction, paraphilic thoughts, and sexual victimization in adulthood, corroborating our initial hypotheses. Only one of the suggested hypotheses was not confirmed, since no association between alcohol or cocaine as the DOC in adulthood and CM was found on bivariate analysis of this sample; however, on multivariate analyses, cocaine was associated with $\mathrm{CM}$.

The findings of this study corroborate the international literature, which points to a higher prevalence of sexual and physical abuse during childhood among substancedependent adults. ${ }^{5,6,23} \mathrm{CM}$ and addiction include a wide range of complex social and economic ramifications. ${ }^{34}$ There is extensive evidence associating $\mathrm{CM}$ with a variety of negative physical and mental health consequences throughout the life cycle. ${ }^{6,18,19}$

Two models have been used to explain such negative outcomes. The first one posits that individuals with a history of child abuse (sexual, physical, and emotional) are likely to experience general problems related to emotions and behavior. The second pattern suggests that certain types of abuse in childhood are associated with specific outcomes in adulthood. Among substance users, different types of abuse are uniquely associated with specific negative effects. ${ }^{17}$ For example, a North American cross-sectional study conducted by Banducci et al. in a group of 280 drug-dependent patients revealed that a history of child sexual abuse predicted exchange of sex for cocaine and heroin, increased number of arrests for prostitution, unprotected sex practices with a casual partner during the year prior to the interview, and experiencing low sexual arousal when sober. In this same study, physical abuse exclusively predicted the number of arrests for robbery and weapon-related offenses. ${ }^{6}$ Although there is no substantial support for the general model, the differential model provides greater specificity for the hypothetical relationship between certain types of abuse and specific outcomes. ${ }^{6}$

Physical and sexual abuse plus the association with consequences of substance abuse in patients admitted to a detoxification program were assessed in a study conducted by Liebschutz et al. The results revealed high levels of physical or sexual abuse among both men (81\%) and women (69\%). This study also highlighted the vulnerability of women to sexual and physical abuse at all stages of life after the initial victimization experience. ${ }^{35}$

An important finding refers to gender issues; it is worth observing that, in our sample, female drug users reported higher percentages of sexual abuse and physical negligence in childhood when compared to men. Numerous forms of violence against women may occur at any stage of the life cycle, since violence is rooted in cultural discrimination and gender submission (i.e., a condition of inferiority compared to men). These findings corroborate data from other studies which reported that drug users, mainly women, report high rates of abuse exposure in childhood. . $^{8,19}$

Another curious finding in this sample was found in relation to religion: non-Catholics reported more emotional abuse when compared to Catholics. This seems to make perfect sense, as Brazil is defined by religious pluralism in regard to the public expression of religion; however, the various denominations of Christianity have imposed their representations. The hegemony of Christianity in Brazil has negatively impacted African-Brazilian religions, with increased religious intolerance in the 
Table 3 Sex-related conditions, child abuse and neglect (physical, emotional, sexual), and CTQ domains ( $\mathrm{n}=134$ )

\begin{tabular}{|c|c|c|c|c|c|c|c|}
\hline & \multirow[b]{2}{*}{ Total } & \multicolumn{2}{|c|}{ Neglect } & \multicolumn{3}{|c|}{ Abuse } & \multirow[b]{2}{*}{ CTQ* (mean rank) } \\
\hline & & Physical & Emotional & Physical & Sexual & Emotional & \\
\hline \multicolumn{8}{|l|}{ Sexual orientation ${ }^{\dagger \ddagger}$} \\
\hline Homosexual & 8.5 & 80.0 & 90.0 & 60.0 & 10.0 & 80.0 & 34.4 \\
\hline Heterosexual & 80.3 & 87.4 & 97.7 & 67.8 & 39.1 & 93.1 & 55.6 \\
\hline Bisexual & 7.7 & 75.0 & 100.0 & 100.0 & 50.0 & 100.0 & 72.4 \\
\hline No sexual attraction & 3.4 & 100.0 & 100.0 & 100.0 & - & 100.0 & 57.5 \\
\hline \multicolumn{8}{|l|}{ Sex addiction** } \\
\hline Yes & 28.4 & 85.7 & 95.2 & 61.9 & 32.1 & 88.1 & 71.4 \\
\hline No & 71.6 & 86.8 & 100.0 & 89.5 & 39.5 & 89.5 & 57.0 \\
\hline \multicolumn{8}{|l|}{ Paraphilic thoughts** } \\
\hline Yes & 28.4 & 97.3 & 100 & 75.7 & 29.7 & 78.4 & 59.3 \\
\hline No & 64.2 & 81.2 & 95.3 & 68.2 & 36.5 & 92.9 & 62.4 \\
\hline \multicolumn{8}{|c|}{ Condom use with stable partner* ${ }^{*}$} \\
\hline Yes & 38.7 & 97.7 & 100.0 & 75.0 & 34.1 & 88.6 & 63.3 \\
\hline No & 61.3 & 80.6 & 94.4 & 69.4 & 33.3 & 87.5 & 55.5 \\
\hline \multicolumn{8}{|c|}{ Condom use with casual partner* ${ }^{*}$} \\
\hline Yes & 73.4 & 86.7 & 97.3 & 80.0 & 40.0 & 90.7 & 56.1 \\
\hline No & 26.6 & 85.7 & 92.9 & 60.7 & 35.7 & 92.9 & 41.0 \\
\hline \multicolumn{8}{|c|}{ Exchange of sexual favors for drugs $* *$} \\
\hline Yes & 12.0 & 78.6 & 100.0 & 92.9 & 78.6 & 100.0 & 89.9 \\
\hline No & 88.0 & 86.4 & 96.1 & 66.0 & 30.1 & 87.4 & 54.8 \\
\hline \multicolumn{8}{|l|}{ Masturbation* } \\
\hline Yes & 28.4 & 80.6 & 100.0 & 80.6 & 36.1 & 88.9 & 68.0 \\
\hline No & 71.6 & 88.4 & 95.3 & 66.3 & 33.7 & 88.4 & 58.8 \\
\hline \multicolumn{8}{|c|}{ Homosexual intercourse $* \hbar$} \\
\hline Yes & 25.8 & 80.6 & 96.8 & 80.6 & 54.8 & 93.5 & 75.6 \\
\hline No & 74.2 & 87.8 & 96.7 & 66.7 & 27.8 & 86.7 & 55.9 \\
\hline \multicolumn{8}{|c|}{ Human immunodeficiency virus infection ${ }^{* \ddagger}$} \\
\hline Yes & 5.2 & 85.7 & 100.0 & 57.1 & 42.9 & 100.0 & 44.0 \\
\hline No & 94.8 & 86.1 & 96.5 & 71.3 & 33.9 & 87.8 & 62.6 \\
\hline \multicolumn{8}{|l|}{ Sexual abuse*t } \\
\hline Yes & 17.4 & 76.2 & 100.0 & 90.5 & 85.7 & 95.2 & 84.7 \\
\hline No & 82.6 & 88.0 & 96.0 & 66.0 & 24.0 & 87.0 & 49.3 \\
\hline
\end{tabular}

Data presented as \%, unless otherwise specified.

Values in bold are statistically significant.

$\mathrm{CTQ}=$ Childhood Trauma Questionnaire; $\mathrm{df}=$ degrees of freedom.

$*$ Mann-Whitney $U,{ }^{\dagger}$ Kruskal-Wallis, ${ }^{\ddagger}$ Chi-square $\left(\chi_{[\mathrm{df}]}^{2}\right)$.

country as seen in regards to other religions around the world. $^{36,37}$ The National Secretariat of Human Rights reported 697 cases of religious intolerance in the states of São Paulo, Rio de Janeiro, and Minas Gerais, Brazil, between 2011 and December 2015. In the state of Rio de Janeiro, Centro de Promoção da Liberdade Religiosa e Direitos Humanos (CEPLIR), the agency which protects and promotes religious freedom and human rights, reported 1,014 cases between July 2012 and August 2015, of which $71 \%$ were against followers of African-based religions, $7.7 \%$ against Evangelical Christians, 3.8\% against Catholics, $3.8 \%$ against Jews, and $3.8 \%$ against religious freedom in general. It is believed that the impact of experiencing religious intolerance in early life may have repercussions in the future, aside from being in a human rights violation. ${ }^{38}$

In our sample, there was no significant association between sexual abuse and other sociodemographic characteristics, nor DOC. The same was found in a literature review conducted by Verdolini et al., which showed that, even though sexual abuse has been studied extensively, neglect, physical, and emotional abuse appear to be more frequent within the population of patients who have suffered any type of abuse. ${ }^{39}$

In our sample, alcohol, tobacco, and cocaine were the predominant DOCs. Individuals who had experienced emotional abuse had elevated levels of tobacco use. Cocaine and cannabis use were related to emotional and physical neglect. The average CTQ values for any form of maltreatment were higher in alcohol and cocaine users - as expected, as a way to cope with the early trauma of CM. These data corroborate the findings of Banduci et al., who described an association between alcohol/cocaine use and elevated CM rates in adults. In this study, the authors observed a potential for comorbid psychiatric disorder among participants with alcohol dependence (OR 9.9), cocaine dependence (OR 5.3), or opioid dependence (OR 4.7) when compared to those with no history of $\mathrm{CM}^{40}$ 
Table 4 Final logistic regression model for child abuse and neglect (physical, emotional, sexual)

\begin{tabular}{|c|c|c|c|c|c|}
\hline & \multicolumn{2}{|c|}{ Neglect } & \multicolumn{3}{|c|}{ Abuse } \\
\hline & Physical & Emotional & Physical & Sexual & Emotional \\
\hline Female & - & - & $4.8(2.50-8.88)$ & $3.8(1.42-7.43)$ & - \\
\hline Single & $4.1(1.53-10.98)$ & - & - & - & - \\
\hline Caucasian & $3.9(1.49-10.20)$ & $4.8(2.1-7.38)$ & - & - & $2.7(1.10-5.05)$ \\
\hline Catholic & - & $5.4(1.48-8.04)$ & $2.6(1.07-5.65)$ & - & $3.0(1.19-7.68)$ \\
\hline Heterosexual & - & - & - & $3.9(1.35-6.61)$ & $2.9(1.14-6.44)$ \\
\hline Sex addiction & $6.5(2.22-9.02)$ & $7.5(2.32-9.20)$ & $5.9(2.38-9.04)$ & - & - \\
\hline Exchanges sexual favors for drugs & - & - & - & $5.7(1.35-9.64)$ & - \\
\hline
\end{tabular}

Data presented as odds ratio (95\% confidence interval).

Other studies have found that adult victims of child sexual abuse have high rates of healthcare utilization and significantly more health complaints when compared to adults with no such history, ${ }^{30,41}$ in addition to higher rates of psychoactive substance use,,${ }^{6,10}$ resulting in increased social and health costs. ${ }^{30}$ Physical and sexual abuse in childhood is a major factor for risk-taking behaviors, including substance abuse, self-harm, prostitution, and increased vulnerability to further sexual assault. High-risk behaviors, in turn, may lead to long-term physical health problems. Victims of sexual abuse, for example, may be prone to sexually transmitted infections. ${ }^{34}$

There is a vast body of literature emphasizing the role of victimization during childhood, along with risk contexts such as transactional sex, ${ }^{42}$ compulsive sex behaviors, ${ }^{43}$ and overdose risk ${ }^{44}$ as predictors of long term disorders, pathways to personality disorders, ${ }^{45}$ comorbidity, suicide attempts, polydrug abuse,$^{24,46,47}$ and relapse in drugdependent individuals over the course of their adult life. ${ }^{48,49}$ This shows that $\mathrm{CM}$ should be seriously taken into consideration when assessing the type of treatment required, as it represents a major risk factor for drug addiction and other mental disorders. ${ }^{49,50}$ The overlap between early trauma and later substance dependence poses a significant challenge in treatment of comorbidities. 8,19

In our sample, one-third of drug users who reported physical abuse in childhood endorsed a SAST score of 6 points or higher, and childhood sexual abuse increased the odds of paraphilic thoughts in adulthood. As anticipated in our hypothesis, to have suffered abuse in childhood is a significant predictor of high-risk sexual behavior in adulthood. Previous evidence points out that childhood abuse potentially increases the risk for sex addiction and paraphilic thoughts in adulthood. ${ }^{31,51}$ This association was also observed in a study by Hall in which he assessed the childhood of sex addicts and found that $38 \%$ had been emotionally abused, $17 \%$ had been sexually abused, and $16 \%$ had been physically abused. ${ }^{51}$

Hahn et al. found that alexithymia accounted for a significant part of the relationship between $\mathrm{CM}$ and highrisk sexual behavior in a sample of 425 sexually active college undergraduates. Moreover, the association between alexithymia and sexual risk-taking was fully accounted for in two separate behaviors. First, negative urgency and subsequent alcohol use partially mediated the relationship, while the second outcome was accounted for by a needy interpersonal style. ${ }^{52}$
All of these findings suggest the importance of assessing for childhood abuse and neglect experiences among patients with substance dependence disorder, in order to develop appropriate early intervention and harmreduction strategies.

This study has a number of limitations. One is the selfadministered nature of the instrument. This may have produced a biased interpretation, especially in a population with low educational level, such as our sample. However, investigating a history of violence and traumatic events in any population means addressing highly sensitive issues, which create embarrassment, guilt, and fear. Studies that preserve the respondents' identity and do not result in judgment of the participants tend to generate more reliable data and benefits for those who participate.

Recall bias also may have occurred in this study, as our questionnaire assesses events that occurred in childhood. The cross-sectional nature of the study does not allow for causal inference, and - as in all observational studies - there may be some unmeasured confounders that were not captured and considered in the analysis. The literature supports a strong relationship between childhood maltreatment and mental illness, but most studies reviewed are cross-sectional and/or used recall to assess maltreatment, and are thus prone to temporality and recall bias. ${ }^{50}$ Since a convenience sample was used, our findings cannot be generalized.

Individual consultants who have continuous contact with children, such as schoolteachers and providers in community health services, could have a leading role in recognizing, responding to, and supporting children who have experienced maltreatment. Health professionals such as nurses, dentists, doctors, and social workers should be advised to observe a child's appearance and behavior and look for any physical or emotional signs of abuse $^{34}$ in various health settings, particularly addiction treatment. These findings have important implications for the daily practice of preventing child abuse. Preventing $\mathrm{CM}$ is not a political priority in many countries around in the world, despite the importance of this problem and increasing awareness of its high social costs. ${ }^{1}$ Furthermore, our findings also have implications for clinical settings designed for substance dependence treatment. They may help implementation of interventional strategies by health professionals; because of the high prevalence of $\mathrm{CM}$, these issues need to be addressed with a view to preventing relapse and improving prognosis. ${ }^{6,10,11}$ Identifying and treating persons with CM may have a significant 
impact on public health. Our findings support the notion that substance abuse treatment should include screening for $\mathrm{CM}$ and integrated interventions to address common sequelae of abuse (e.g., posttraumatic stress disorder and suicide risk), as previously recommended. ${ }^{53}$ Drug users with a history of $\mathrm{CM}$ require intensive secondary suicide prevention efforts. ${ }^{54}$ The integration of preventive interventions within programs frequently accessed by drug users, such as community health clinics, requires increased attention, consideration, and evaluation. ${ }^{53}$

$\mathrm{CM}$ is a human rights violation, as well as a complex public health issue. It is the most important preventable cause of psychopathology, accounting for about $45 \%$ of the population's attributable threat for childhood-onset psychiatric disorders. ${ }^{55}$ It is also associated with multiple adverse outcomes in adulthood, including poor mental health and violence. This has important implications for primary prevention efforts, and highlights the need for effective programs and policies to reduce its occurrence. In this context, prevention strategies should prioritize and focus on early-childhood exposure to violence in the family environment. ${ }^{56}$ Intervening at an early stage with proper parenting programs may reduce a child's risk of developing long-term health and psychological problems and reduce the public health burden of $\mathrm{CM}$ by preventing future health problems and revictimization in adulthood, along with its negative consequences, such as alcohol and drug dependence. ${ }^{34}$

Research on the potential prospective impact of $\mathrm{CM}$ reduction on the incidence of psychiatric morbidities is scarce, and should be one of the challenges addressed in future studies. ${ }^{50}$

In conclusion, adults with substance use problems report high rates of physical and sexual abuse in childhood, especially women. CM is associated with sexual revictimization and conditions of high-risk sexual behavior in later life, including sex addiction, paraphilic thoughts, and exchange of sexual favors for drugs.

\section{Disclosure}

The authors report no conflicts of interest.

\section{References}

1 World Health Organization (WHO). Preventing child maltreatment: a guide to taking action and generating evidence [Internet]. 2006 [cited 2018 Aug 27]. www.who.int/violence_injury_prevention/publications/ violence/child maltreatment/en/

2 World Health Organization (WHO). Global status report on violence prevention [Internet]. 2014 [cited 2018 Aug 27]. www.who.int/ violence_injury_prevention/violence/status_report/2014/en/

3 Maranhão F. Brasil registra três queixas de abuso sexual de crianças por hora [Internet]. UOL Notícias. 2015 May 28 [cited 206 Apr 29] noticias.uol.com.br/cotidiano/ultimas-noticias/2015/05/18/tres-queixasde-abuso-e-exploracao-sexual-de-criancas-sao-feitas-por-hora.htm

4 Unidade de Pesquisa em Álcool e Drogas (UNIAD), Instituto Nacional de Ciência e Tecnologia para Políticas Públicas do Álcool e outras Drogas (INPAD). II Levantamento Nacional de Álcool e Drogas (LENAD) [Internet]. 2012 [cited 2016 Apr 26]. inpad.org.br/wp-content/ uploads/2014/03/Lenad-II-Relat\%C3\%B3rio.pdf

5 Zanoti-Jeronymo DV, Zaleski M, Pinsky I, Caetano R, Figlie NB, Laranjeira R. [Prevalence of physical abuse in childhood and exposure to parental violence in a Brazilian sample]. Cad Saude Publica. 2009;25:246779.

6 Banducci AN, Hoffman E, Lejuez CW, Koenen KC. The relationship between child abuse and negative outcomes among substance users: psychopathology, health, and comorbidities. Addict Behav. 2014;39: $1522-7$.

7 Darke S, Torok M. The association of childhood physical abuse with the onset and extent of drug use among regular injecting drug users. Addiction. 2014;109:610-6.

8 Najavits LM, Weiss RD, Shaw SR. The link between substance abuse and posttraumatic stress disorder in women. A research review. Am J Addict. 1997;6:273-83.

9 Elliott JC, Stohl M, Wall MM, Keyes KM, Goodwin RD, Skodol AE, et al. The risk for persistent adult alcohol and nicotine dependence: the role of childhood maltreatment. Addiction. 2014;109:842-50.

10 Banducci AN, Hoffman EM, Lejuez CW, Koenen K. The impact of childhood abuse on inpatient substance users: specific links with risky sex, aggression, and emotion dysregulation. Child Abuse Negl. 2014; 38:928-38.

11 Arellano CM. Child maltreatment and substance use: a review of the literature. Subst Use Misuse. 1996;31:927-35.

12 Garner BR, Hunter BD, Smith DC, Smith JE, Godley MD. The relationship between child maltreatment and substance abuse treatment outcomes among emerging adults and adolescents. Child Maltreat. 2014;19:261-9.

13 Moran PB, Vuchinich S, Hall NK. Associations between types of maltreatment and substance use during adolescence. Child Abuse Negl. 2014;28:565-74.

14 Minh A, Matheson FI, Daoud N, Hamilton-Wright S, Pedersen C, Borenstein $\mathrm{H}$, et al. Linking childhood and adult criminality: using a life course framework to examine childhood abuse and neglect, substance use and adult partner violence. Int $\mathrm{J}$ Environ Res Public Health. 2013;10:5470-89.

15 Schwandt ML, Heilig M, Hommer DW, George DT, Ramchandani VA. Childhood trauma exposure and alcohol dependence severity in adulthood: mediation by emotional abuse severity and neuroticism. Alcohol Clin Exp Res. 2013;37:984-92.

16 Smith PH, Saddleson ML, Homish GG, McKee SA, Kozlowski LT, Giovino GA. The relationship between childhood physical and emotional abuse and smoking cessation among U.S. women and men. Psychol Addict Behav. 2015;29:338-46.

17 Senn TE, Carey MP. Child maltreatment and women's adult sexual risk behavior: childhood sexual abuse as a unique risk factor. Child Maltreat. 2010;15:324-35.

18 Golder S, Logan TK. Violence, victimization, criminal justice involvement, and substance use among drug-involved men. Violence Vict. 2014;29:53-72.

19 Mejía B, Zea P, Romero M, Saldívar G. Traumatic experiences and re-victimization of female inmates undergoing treatment for substance abuse. Subst Abuse Treat Prev Policy. 2015;10:5.

20 Senn TE, Carey MP, Vanable PA, Coury-Doniger P, Urban MA. Childhood sexual abuse and sexual risk behavior among men and women attending a sexually transmitted disease clinic. J Consult Clin Psychol. 2006;74:720-31.

21 Chen G, Gueta K. Child abuse, drug addiction and mental health problems of incarcerated women in Israel. Int $\mathrm{J}$ Law Psychiatry. 2015;39:36-45.

22 Kristman-Valente A, Wells EA. The role of gender in the association between child maltreatment and substance use behavior: a systematic review of longitudinal research from 1995 to 2011. Subst Use Misuse. 2013;48:645-60.

23 Winham KM, Engstrom M, Golder S, Renn T, Higgins GE, Logan TK Childhood victimization, attachment, psychological distress, and substance use among women on probation and parole. Am J Orthopsychiatry. 2015;85:145-58.

24 Armour C, Shorter GW, Elhai JD, Elklit A, Christoffersen MN. Polydrug use typologies and childhood maltreatment in a nationally representative survey of Danish young adults. J Stud Alcohol Drugs. 2014;75:170-8.

25 Miller M. A model to explain the relationship between sexual abuse and HIV risk among women. AIDS Care. 1999;11:3-20.

26 Ulibarri MD, Ulloa EC, Salazar M. Associations between mental health, substance use, and sexual abuse experiences among Latinas. J Child Sex Abus. 2015;24:35-54 
27 Viola TW, Salum GA, Kluwe-Schiavon B, Sanvicente-Vieira B Levandowski ML, Grassi-Oliveira R. The influence of geographical and economic factors in estimates of childhood abuse and neglect using the Childhood Trauma Questionnaire: a worldwide metaregression analysis. Child Abuse Negl. 2016;51:1-11.

28 Clark BC, Perkins A, McCullumsmith CB, Islam AM, Sung J, Cropsey KL. What does self-identified drug of choice tell us about individuals under community corrections supervision? J Addict Med. 2012;6:57-67.

29 Bernstein D, Fink L. Childhood trauma questionnaire: a retrospective self-report. San Antonio: Psychological Corporation; 1998.

30 Grassi-Oliveira R, Stein LM, Pezzi JC. [Translation and content validation of the Childhood Trauma Questionnaire into Portuguese language]. Rev Saude Publica. 2006;40:249-55.

31 Carnes PJ. The sexual addiction. Minneapolis: Comp Care; 1983.

32 Silveira DX, Vieira AC, Palomo V, Silveira ED. Validade de critério e confiabilidade da versão brasileira de uma escala de rastreamento para dependência de sexo. Rev Bras Psiquiatr. 2000;22:4-10.

33 Victora CG, Huttly SR, Fuchs SC, Olinto MT. The role of conceptual frameworks in epidemiological analysis: a hierarchical approach. Int J Epidemiol. 1997;26:224-7.

34 Lazenbatt A; NSPCC Reader in Childhood Studies, Queen's University Belfast. The impact of abuse and neglect on the health and mental health of children and young people [Internet]. 2010 Feb [cited 2016 Apr 29]. www.childmatters.org.nz/file/Diploma-Readings/ Block-2/Neglect/ 4.5-impact-of-abuse-and-neglect-on-health-mh-updated.pdf.

35 Liebschutz J, Savetsky JB, Saitz R, Horton NJ, Lloyd-Travaglini C, Samet $\mathrm{JH}$. The relationship between sexual and physical abuse and substance abuse consequences. J Subst Abuse Treat. 2002;22: 121-8.

36 Lui JA. Os rumos da intolerância religiosa no Brasil. Relig Soc. 2008; 28:211-4.

37 Caputo SG. Aprendendo yorubá nas redes educativas dos terreiros: história, culturas africanas e enfrentamento da intolerância nas escolas. Rev Bras Educ. 2015;20:773-96.

38 Rio de Janeiro. Centro de promoção à liberdade religiosa e direitos humanos (CEPLIR) [Internet]. 2016 Mar 09 [cited 2018 Aug 28]. www.rj.gov.br/web/seasdh/exibeconteudo?article-id=2758410

39 Verdolini N, Attademo L, Agius M, Ferranti L, Moretti P, Quartesan R. Traumatic events in childhood and their association with psychiatric illness in the adult. Psychiatr Danub. 2015;27:S60-70.

40 Banducci AN, Hoffman E, Lejuez CW, Koenen KC. The relationship between child abuse and negative outcomes among substance users: psychopathology, health, and comorbidities. Addict Behav. 2014;39: 1522-7.

41 Sachs-Ericsson N, Blazer D, Plant EA, Arnow B. Childhood sexual and physical abuse and 1-year prevalence of medical problems in the national comorbidity survey. Health Psychol. 2005;24:32-40.
42 Verona E, Murphy B, Javdani S. Gendered pathways: violent childhood maltreatment, sex exchange, and drug use. Psychol Violence. 2015 Apr 20;2015. pii: a0039126.

43 Vaillancourt-Morel MP, Godbout N, Labadie C, Runtz M, Lussier Y, Sabourin S. Avoidant and compulsive sexual behaviors in male and female survivors of childhood sexual abuse. Child Abuse Negl. 2015;40:48-59.

44 Lake S, Hayashi K, Milloy MJ, Wood E, Dong H, Montaner J, et al. Associations between childhood trauma and non-fatal overdose among people who inject drugs. Addict Behav. 2015;43:83-8.

45 Brents LK, Tripathi SP, Young J, James GA, Kilts CD. The role of childhood maltreatment in the altered trait and global expression of personality in cocaine addiction. J Psychiatr Res. 2015;64:23-31.

46 Kilpatrick DG, Saunders BE. Prevalence and consequences of child victmization: results from the national survey of adolescents, final report [Internet]. 1997 Nov [cited 2018 Aug 28]. www.ncjrs.gov/ pdffiles1/nij/grants/181028.pdf

47 Sacks JY, McKendrick K, Banks S. The impact of early trauma and abuse on residential substance abuse treatment outcomes for women. J Subst Abuse Treat. 2008;34:90-100.

48 Elton A, Smitherman S, Young J, Kilts CD. Effects of childhood maltreatment on the neural correlates of stress- and drug cueinduced cocaine craving. Addict Biol. 2015;20:820-31.

49 Henriksen CA, Stein MB, Afifi TO, Enns MW, Lix LM, Sareen J. Identifying factors that predict longitudinal outcomes of untreated common mental disorders. Psychiatr Serv. 2015;66:163-70.

50 Li M, D'Arcy C, Meng X. Maltreatment in childhood substantially increases the risk of adult depression and anxiety in prospective cohort studies: systematic review, meta-analysis, and proportional attributable fractions. Psychol Med. 2016;46:717-30.

51 Hall P. Understanding and treating sex addiction: a comprehensive guide for people who struggle with sex addiction and those who want to help them. London: Routledge; 2013.

52 Hahn AM, Simons RM, Simons JS. Childhood maltreatment and sexual risk taking: the mediating role of alexithymia. Arch Sex Behav. 2016;45:53-62

53 La Flair LN, Reboussin BA, Storr CL, Letourneau E, Green KM, Mojtabai $\mathrm{R}$, et al. Childhood abuse and neglect and transitions in stages of alcohol involvement among women: a latent transition analysis approach. Drug Alcohol Depend. 2013;132:491-8.

54 Marshall BD, Galea S, Wood E, Kerr T. Longitudinal associations between types of childhood trauma and suicidal behavior among substance users: a cohort study. Am J Public Health. 2013;103:e69-75.

55 Teicher $\mathrm{MH}$, Samson JA. Annual research review: enduring neurobiological effects of childhood abuse and neglect. J Child Psychol Psychiatry. 2016;57:241-66.

56 González RA, Kallis C, Ullrich S, Barnicot K, Keers R, Coid JW. Childhood maltreatment and violence: mediation through psychiatric morbidity. Child Abuse Negl. 2016;52:70-84. 